\title{
The Nature of Roles on Health and Well-Being of Older Adults in Congregant Living
}

\author{
Theodore Alter \\ Social Work Program, School of Social and Behavioral Sciences, Stockton University, Galloway, NJ, USA \\ Email: theodore.alter@stockton.edu
}

How to cite this paper: Alter, T. (2017) The Nature of Roles on Health and Well-Being of Older Adults in Congregant Living. Open Journal of Social Sciences, 5, 29-52. https://doi.org/10.4236/jss.2017.59003

Received: August 1, 2017

Accepted: August 29, 2017

Published: September 1, 2017

Copyright (C) 2017 by author and Scientific Research Publishing Inc. This work is licensed under the Creative Commons Attribution International License (CC BY 4.0).

http://creativecommons.org/licenses/by/4.0/

\begin{abstract}
This study examined the functional and psychological abilities of newly admitted female residents to several continuing care retirement communities (CCRC's) in central New Jersey in an attempt to understand why some residents rapidly suffer functional and emotional decline, while others do not. The study supports previous findings that membership in roles promotes health and well-being, but the quantity of roles may be equal to or even less a factor than consistency of membership in even a single role. While membership in many roles has been proven to enhance the quality of life for older adults, membership in a single role may offer the same benefits.
\end{abstract}

\section{Keywords}

CCRC, Roles, Life Course, Health and Well-Being

\section{Introduction}

Many residents' functional and psychosocial abilities were found to dramatically deteriorate soon after moving into several continuing care retirement communities (CCRC's) in central New Jersey. This problem was widespread, affecting about one in three new residents who had moved into the respective community. Although there were provisions for personal care aides to meet residents' physical care needs, the care-intensive needs of these newly accepted residents often exhausted staff resources. Increased telephone calls, continual prompting and reminding, emotional support and constant emergency interventions, taxed the staff's ability to meet the needs of all independent living residents. The most troubling consequence of the rapid functional and cognitive decline among new move-ins was to their quality of life. Their peers view them negatively, which affects their ability to acclimate to the community. Even more importantly, 
residents who led active, vibrant, independent lives only months earlier, now face loss of independence and constant intrusions and supervision from staff providing for their necessary care. Ultimately, many of these residents became depressed. To many, an independent living community with five star amenities now simply became a monotonous place in which to wait to die.

Are people healthier because they are entrenched in multiple roles or are people more likely to have multiple roles and be involved in multilayered social networks because they are healthier? Which comes first, health or social relationships (Wethington et al., 2002) [1]? The question becomes not whether multiple roles are a function of health, or whether health is a function of multiple roles. Rather, what are the pathways to social integration and health in the latter years of adulthood (Moen, Dedmpster \& Williams, 1992) [2]? A life-course perspective offers a paradigm in which to study aging because it seeks to understand how circumstances in an earlier phase of life may affect health and social integration as an older adult. A life-course perspective is a heuristic model in which to conceptualize an individual's life within the context of his family, society and historical time by examining the frequencies and the timing of changes of roles (Elder, 1985 [3]; Moen et al., 1992 [2]; Elder, 1995 [4]).

The life course model promotes the idea that individuals' place preferences are determined in part, by the life stage. "The unit of analysis becomes the individual sited in geographical, social, historical and political space and the study of the household becomes the study of conjoined life-courses" (Boyle, Halfacree \& Robinson, 1998, p. 110) [5].

Walters submits that life course studies of elderly migration focus on three primary goals:

1) identifying the events most closely associated with geographic mobility in later life, 2) classifying and describing the individuals most likely to move in response to each event and 3) identifying and assessing the place characteristics most often associated with the mobility of each migrant (Walters 2002, p. 39) [6].

Litwak and Longino (1987) [7] proposed a developmental subcategory of the life course model. The researchers have suggested that the nature of the modernindustrial world places institutional pressures to make three basic types of moves: one when they retire, a second when they experience moderate forms of disability, and a third when they experience major forms of chronic disability (Litwak \& Longino, 1987 [7]; De Jong et al., 1995 [8]; Walters, 2000 [6]). The first social pressure to move occurs with retirees with intact marriages and sufficient income. Family relationships are manageable over long distances. This group of older adults is healthier and wealthier. They are looking for locations that provide attractive amenities and services. The pressure for the second move occurs when older adults develop chronic disabilities. They are no longer capable of independently carrying out everyday tasks like shopping, cooking and 
cleaning. Where a spouse may have been able to provide needed assistance, the death of that spouse compounds the pressure for moving; family relationships are no longer possible long distance, and the older adult moves to be closer to their family. The third move occurs when the disability becomes so severe or health has so deteriorated that families are no longer capable of meeting the person's needs or there is simply no family. This individual is forced to seek assistance within their community or within an institutional setting.

Researchers suggest that life stage does not fully explain later life (Oswald, Schilling, Hans-Werner, \& Karen 2002) [9]; Walters (2000) [6] introduced the concept of intention and enabling attributes. Intention is to take advantage of an amenity. Enabling are individual characteristics that allow the individual to take advantage of particular amenities. Oswald et al. (2002) [9] reported four reasons for moving, household amenities, stimulation, availability of resources, and social network. Relocation is therefore a multidimensional process. It is an "ecological transition that can take place at any point throughout the lifespan" (Oswald et al., 2002, p. 284) [9]. Folts \& Muir (2002) [10] report that a number of researchers have found that elderly housing patterns are indistinguishable from general housing patterns (Oswald et al., 2002 [9]; Folts \& Streib, 1994 [11]; Golant, 1992 [12]; Lawton 1975 [13]; Mangum, 1994 [14]; Pynoos, 1990 [15]; Streib, Folts \& Hilker, $1984[16])$.

Folts and Muir (2002) [10] report migrants aging in place expressed high levels of satisfaction with their current location. The researchers found that the retirees who are most likely to be relocated are those with the fewest connections, those with the least compatible lifestyle and those with the economic, health and psychic resources to move. Dr. Robert Butler, former head of the National Institute on Aging was quoted as saying, "The best place to retire is in the neighborhood where you spent your life" (Longino et al., 2002, p. 45) [17].

Nelson and Winter (1975) [18] suggest that motivation to move is linked to three factors: the occurrences of major life disruptions, low levels of personal independence and reduced levels of housing and neighborhood satisfaction (Wiseman \& Roseman, 1979) [19]. They believe that the conditions of the dwelling and the neighborhood must be considered relative to perceived conditions. The researchers offered a number of intermediate characteristics such as personal characteristics, perceived housing discrepancies, perceived neighborhood discrepancies, social bonds, expected financial consequences of moving, expected negative consequences of moving on social contacts and expected possibilities on the housing market. Similarly, the effect of deteriorating health and functional status, particularly from falls, lend support to the idea of older adults anticipating relocation (Silverstein \& Zablotsky, 1996 [20]; Stoeckel \& Porell, 2010 [21]).

A number of search engines were used in order to obtain the most current research. These included Social Sciences and Social Work Databases, Social Work Abstracts, ProQuest Central, YU FIND SOC, and Google Scholar. The paucity of much current literature emphasizes the need for additional research in this area. 
Still, the literature is replete with studies demonstrating that the quantity and quality of roles are positively correlated to health (Lowenthal \& Haven, 1968 [22]; George, 1996 [23]; Throits, 1983 [24]; Verbrugge, 1983 [25]; Moen et al., 1992 [2]). But are healthy people more likely to possess more roles, or are they likely to be engaged in more roles because they are healthier (Wethington et al., 2000) [1]? Moreover, how do we account for healthier older adults who do not possess those multiple roles? Which came first, the chicken or the egg?

Verbrugge (1983) [25] found that healthy people are able to acquire and keep roles more easily than unhealthy people. She points out that the issue is one of social causation versus social selection. Social causation maintains that social integration influences health while social selection maintains that healthy people are the ones more likely to take on and maintain multiple roles (Wethington et al., 2000) [1]. However, House et al. (1988) [26] suggest that the linking of health with social integration is not clear. In actuality, causation and selection probably function simultaneously and interactively (Wethington et al., 2000) [1].

A social integration model looks at the entire set of an individual's connections to others in his or her environment. This involves examining the individual's participation in meaningful roles and his/her network of social contacts. This paradigm conceives health outcomes as both interdependent and unfolding over time. A role enhancement perspective suggests that regardless of age, men and women with more roles experience higher levels of physical and emotional health than those with fewer roles. Conversely, a role strain perspective emphasizes the cost rather than the benefits of multiple roles. It assumes a fixed quantity of time, energy and commitment are available for family and non-family roles responsibilities. Lastly, a role context perspective proposes that the role involvement in particular circumstances is paramount in order to explain one's health and well-being. Pillemer et al. (2000) [27] suggests:

"a more dynamic, longitudinal, and contextual view of the relationship between health and well-being is necessary. It may not be role occupancy alone but rather the timing, sequencing, duration, or number of spells in particular roles that is consequential for both social integration and emotional well-being" (p. 54).

The life course perspective proposes that the impact of earlier resources and life pathways cannot be understood without reference to issues of timing, trajectories and transitions. Expanding on the work of Elder (1985) [3] Moen et al., (1992) [2] submits that there are three life course themes: timing, process, and context. As mentioned, Verbrugge (1983) [25] found that women who are employed have better health outcomes. Timing suggests that knowing that a woman was employed at some point in her life is less useful that knowing the duration and patterning of her participation in the work force. Process emphasizes that aging is a series of role transitions rather than a solitary event. Some roles are left behind, while new ones are taken. For example, a spouse becomes a widow; an employed worker becomes a retiree. Both timing and process involve role tra- 
jectories, or the way a role is executed over the life course. Role trajectory examines the history of commitment and participation in a given social role across time. The life course theme of context can refer to one's environment, gender, and personal circumstances such as education, marital status and family size. Age may reflect physiological differences and historical circumstances (Moen 1996) [21].

Pillemer et al. (2000) [27] believes that:

"a contextual measurement approach provides a basis for developing a more comprehensive analysis of social integration and health, when combined with social-psychological and life-course perspective" (p. 57). "In our view, the most fruitful path for advancing research on multiple roles, social integration and health in later life is to combine the insights of qualitative research with data derived from empirically rigorous quantitative designs and analytic strategies" (p. 60).

\section{Procedure for Quantitative Data Collection}

Data was gathered both quantitatively and qualitatively. All residents admitted to any of the five CCRC communities chosen for the study were asked to participate. Given the smaller number of older male adults in CCRC's, (as well as the community at large,) the study was limited to investigating the nature of roles with women only. Forty-one individuals ultimately agreed to participate. Of the 38 , one died before the time of the six-month survey, one was unable to complete the second survey due to time constraints, two refused to complete the second survey due to caregiving responsibilities of their spouse, one decided not to continue her involvement for unspecified reasons, and three left too many responses unanswered to be considered. The final potential interview sample was comprised of 30 individuals.

Ten residents with the least decline and ten residents with the greatest decline as indicated by their score on the SF-36 Item Health Survey, SF-36 multi-purpose short form health survey, will be selected for participation in the second portion of the study.

The SF-36 Item Health Survey is a proven instrument with both high reliability and validity. The SF-36 is a multi-purpose, short form health survey. It provides an eight-scale profile of functional health and well-being scores. Four scales measure physical health: physical functioning (PF), Role-Physical (RP), Bodily Pain (BP), and General Health (GH).

Four scales also measure mental health: Vitality (VT), Social Functioning (SF), Role-Emotional (RE), and Mental Health (MH

Factor analytic studies have confirmed that the eight scales account for $80 \%$ $85 \%$ of physical and mental health factors in the U.S. general population. Reliability of the eight scales and the two summary measures using internal consistency and test-retest methods have varied, with most exceeding 0.80 . Reliability for physical and mental summary scores generally exceeded 0.90 . Median relia- 
bility for each of the eight scales was equal to or greater than 0.80, except for SF which was found to have a median reliability of 0.76 . Standard errors of measurement at the $95 \%$ confidence levels for the eight scales and the two summary scales were found to be \pm 6 - 7 points and \pm 13 - 32 points respectively (Rand Health, 2009). The measurement will be made from the SF-36 administered at the time of admission to the community, as compared to the score on the SF-36 administered six months later.

\section{Procedure for Qualitative Date Collection}

The second portion of the study was qualitative, employing grounded theory. Grounded theory provides an inductive process in which to look for common patterns and themes within the timing, process and context of roles. What are the commonalities of the timing, process and context of roles among residents with higher scores on health and wellness? Similarly, what are those commonalities among residents with lower scores on health and wellness?

Residents with the least decline and residents with the greatest decline as indicated by their score on the SF-36 were selected for participation in the second portion of the study. As mentioned above, Patton (2002) [25] maintains that purposeful or extreme case sampling allows subjects to be selected because of their exclusive membership to the communities and the chance to study information rich cases in-depth. The researcher interviewed each of the residents by means of a semi-structured interview. The interview was audio recorded. Questions were open-ended, and probed areas related to roles: timing, process and context vis-à-vis incorporating the grouping of life changes developed by Lin et al. (1997) [28]. Additional questions addressed individual's evaluations and interpretations of events and their experiences as suggested by Giele and Elder (1998) [29]. Data was then coded, and analyzed by means of Grounded Theory (Glaser and Strauss, 2009) [30].

\section{Additional Interview Questions}

1) Did you have any dreams or ambitions as a child? As an adolescent?

What were your hopes and dreams as you entered adulthood?

2) What is your best memory?

3) When you look back on your life, are there any moments which you would categorize as turning points?

4) What are some of your fears and worries?

5) When you think about the future, what are your thoughts and feelings?

6) What are your hopes? How might these be achieved?

\section{Research Questions}

\subsection{Research Question 1 (RQ1)}

Some women who have moved into CCRC's seem to remain healthier both emotionally and physically longer than other women. Although about the same in 
health at the time of moving into the community, some appear to rapidly deteriorate within the first six months of moving in.

\subsection{Sub-Question (SB1)}

Health and well-being have been proven to correlate with one's roles. Are healthy people more likely to possess more roles, or are they likely to be engaged in more roles because they are healthier? A life course perspective should illustrate the interplay of timing, process and context on those roles which foster health and well-being.

\subsection{Hypothesis 1 (H1)}

Healthier women have maintained at least one role consistently longer than less healthy women. (Timing)

\subsection{Hypothesis 2 (H2)}

The roles longest held by healthier women in their earlier years have been transformed into other roles held over into old age. (Process-Role Trajectory)

\subsection{Hypothesis $3(\mathrm{H} 3)$}

The longest held roles of healthier women were subject to fewer assaults of circumstances, i.e., finances, disease, death of family members, etc., than those of less healthier women. (Context)

\subsection{Hypothesis $4(\mathrm{H} 4)$}

Women with the longest held roles have been the beneficiaries of more positive circumstance, such as financial security and education. (Context)

\subsection{Research Question 2 (RQ2)}

Are people healthier because they are entrenched in multiple roles or are people more likely to have multiple roles as a result of the quality of their health?

\section{Results}

The SF36 breaks the survey questions into eight Summary Scores and two Global Scores as discussed in the Methods Chapter. For the purposes of the study physical health was comprised of Physical Functioning (PF), Physical Role Functioning (RP), Bodily Pain (BP), while well-being was comprised of Social Functioning (SF), Role Emotional (RE) and Mental Health (MH). Excel Spreadsheet were used to record the mean, mode, median and standard deviation of each of the scores (See Appendix 7.3). Each of these scores has been graphed. Negative scores, those below the $\mathrm{X}$-axis are indicative of improvement in functioning (See Appendix 7.4).

Respondents, $12,15,16$, and 22 were selected as having most improved physically and mentally, while respondents $6,8,10,14$, and 29 were selected as those 
that most deteriorated physically and emotionally. These nine respondents were selected for interviews. The interviews were recorded using two audio recording devices, a Livescribe Pulse Smartpen, and a Sony MP3 digital recorder as a backup. The nine interviews were transcribed into Word in their entirety and entered into Atlas.ti, version 7.1.8. The transcripts were then coded. Twenty-nine (29) codes were identified.

\subsection{Coding Frequencies}

Identified Codes and Corresponding Frequencies.

\begin{tabular}{|llll|}
\hline Role Transitions & 55 & Siblings & 10 \\
Role: Job & 47 & Spouse & 9 \\
Education & 32 & Children Born & 8 \\
Disease/Illness & 30 & Memory Best & 8 \\
Mood & 27 & Travel & 7 \\
Housing & 27 & Death: Not immed. Family & 7 \\
Religion & 23 & Health & 5 \\
Marriage & 19 & Death of Sibling(s) & 5 \\
Role: Not Job & 19 & Spouse Death & 4 \\
Role Loss & 18 & Children Death & 4 \\
Aspirations & 16 & Children's Education & 2 \\
Relationships & 16 & Parent(s) & 1 \\
Death and/or Dying & 16 & Parent(s) Death & 1 \\
Children & 15 & Finances & 1 \\
Loss & 12 & & \\
\hline
\end{tabular}

\subsection{Interviews}

\subsubsection{The Deteriorated}

$\mathrm{CH}$, (respondent 16, deteriorated.) $\mathrm{CH}$ is an 83-year-old Protestant. She lives with her husband of 60 years. She is a pleasant, modest woman who easily responds to questions but without much detail. She can walk short distances, but with difficulty and in obvious pain. The couple had two children, one of whom died in 2011 at the age of 55 from cancer. $\mathrm{CH}$ reports that she is estranged from her daughter, although they occasionally correspond by phone. $\mathrm{CH}$ is college educated and worked a number of different jobs before marriage and a few after getting married. These included retail store clerk, production worker in manufacturing, a primary grade school teacher and as an office temp. $\mathrm{CH}$ "belonged to women's clubs wherever (I) lived, and church work wherever we lived." Since moving to the CCRC, $\mathrm{CH}$ helped manage the community's Thrift Shop. Within months of moving to the community, $\mathrm{CH}$ developed a chronic neuromuscular disorder. The disease is being treated, but $\mathrm{CH}$ reports little improvement. $\mathrm{CH}$ has all but totally withdrawn from involvement in the community.

DD (respondent 6, deteriorated.) DD is 89 years old and Jewish. She relates in a soft-spoken, sad, often grimacing and excruciating manner. Her husband of 62 years died in 2007. DD reported attending a number of grammar schools.

"My mother used to get rent concessions so we moved around a bit. She was crazy. I mean, I'm pretty sure she was not exactly right. We're going up 
the escalator in Macy's, and she says to me at the top of her voice "I hate Puerto Ricans. They all talk like Donald Duck. Badudududup. I mean if she had said that a couple of years later, she would have had a knife in her back. But that's how she was. She had no sense of, well, she had no sense of propriety. I'll have to say that... She was always nuts. I think she was always was a bad housekeeper. She never cleaned up the house so we always used to hide when somebody rang our bell. We'd make believe we weren't home. And when we did clean it up, and we did, she'd let it go right away. She never kept it up. I think she was really, they had a word for it, well she certainly was arrested development. She was about five years old and by the time she died I would say she was about eight years old emotionally. I mean, she wouldn't kiss you, you would feel like she was taking something from you when she kissed you. At least that's how I felt. I feel that I was an abused child in a lot of ways."

"She had migraines a lot. She once sent me out in the middle of a snowstorm at night, it was dark. She sent me because she wanted a lollipop. Of course, sucking helps her, so I go out for the lollipop. Before I got to the lollipop store I slipped and fell on the ice and I hurt my ankle. Some guy helped me home, but I wouldn't let him come in. My mother wouldn't like that. She wouldn't let my grandmother in! So I go in the house and I say to her 'Ma I hurt my leg.' She said, 'Did you get the lollipops?' I said 'No'. She said "Go to hell'."

"She once went to visit my sister-in-law. My sister-in-law served beef stroganoff. My mother said, 'I didn't know that it comes in cans.' She was a real piece of work anyhow, my mother."

DD reported that "things" got harder for her family during the depression.

"My father's business didn't work out right. He and his brothers were very close. His brothers are all dead now. He's dead too, the whole family. My grandmother, my father's mother, who my mother didn't like by the way, was the one who got her sons to promise they would take care of us after my father died."

DD said that she was about 16 years old when she graduated high school and her father died. She went to college for a year. "My uncle said I could finish after a year, but then I had to go to work. So, I went to business school." She got a part-time job in a department store. Soon after DD went to work for the Department of Justice. She left that job and went to work for a major motion picture studio. DD went back to college where she met her husband. The couple moved from New York to New Jersey. DD attended four different universities. By the time she graduated she earned 158 undergraduate credits, (far more than necessary for graduation). DD and her husband had three children one who is autistic. At one time, he was placed in Willowbrook, an institution with a rather infamous and sordid history. The couple subsequently started their own school 
for autistic children. The school is no longer in existence. The adult child is currently in a state facility. DD and her husband were members of a synagogue, but were not involved. DD painted and did stitchery at one point but has long since stopped.

EW (respondent 32, deteriorated.) EW is a 97-year-old Catholic. She is hearing impaired and walks with a walker with great difficulty and in obvious pain. She has a warm and welcoming smile and manner. She is married to her second husband of 40 years, ten years her junior. Her first marriage ended in divorce after only a few years. She has no children. EW grew up on a farm, one of nine children, and the only living child. She said that her family was very fortunate during the depression. "We were never hungry. We always had food, and while we couldn't go out and be getting very expensive things we were never hungry." She spoke warmly of her childhood and her mother.

"We are Catholic, and had a great spiritual life. My mother was very religious and I think in a very practical way, even though, and so she had tremendous faith and courage, very tremendous foresight. She saw that we were all educated to the extent that we choose to be, and had vision."

EW graduated from Duke University in Library Science. "My mother said to me, "If you're going to a college, well, you've always wanted to be a librarian, here's your chance, just like that, and right out of the blue." EW married soon after graduating and worked as a legal secretary. She subsequently worked as an assistant librarian for a large NYC entertainment agency. Her marriage ended seven years later. She later moved to Michigan to help her sister care for her ill husband. EW reports setting up the entire public library for the city. She returned to New York and worked as the librarian for the same entertainment agency. EW obtained dispensation from the Church and married her current husband. They returned to New Jersey to work on her parent's farm. EW also became the township librarian. EW said that moving to the community was difficult. She proudly displays a picture of their home, which resembles a Norman Rockwell painting. EW said that this was

"Not just the house that was difficult to leave, but the people. Here, you make no friends because nobody wants to be a friend. Nobody... I get the feeling, this is my feeling, that nobody looks like it's permanent-like. Do you know what I'm saying?... It's more like they're acquaintances, not friends."

MF, (respondent 8, deteriorated.) MF is a 90 -year-old Catholic widow. She exhibits a moderate level of dementia particularly evident by short-term memory loss. She also appears much younger than her stated age. MF walks without an assistive device. She is neither hard of hearing or sight impaired. MF is the only surviving member of a family of five children. She attended parochial school through high school. The elementary school she attended was in the same church in which her mother married. She attended business school and then 
worked for a company where she met her husband. He developed tuberculosis soon after they married and was institutionalized for treatment for two years. MF was pregnant during that time. She and her husband had five children. MF remarked that she was a "stay-at-home mom... I had a good thing going." Their oldest son worked in the World Trade Center and died on September 11, 2001. "Yeah, that was horrible. But the best part about it was we found his body on Tuesday. I think it happened on a weekend, but they found his body on a Tuesday morning." MF added that her youngest son's wife died suddenly at the age 43. MF's husband died about ten years ago. MF reports that she takes no medication except for high blood pressure "and it's under control". She said that she "hopes to die a peaceful death... not where somebody has to take care of me and I don't know what I'm doing."

SG, (res SG, (respondent 11, deteriorated). SG is 89-year-old Jewish woman. She was the youngest of four children and the only surviving child. She lives with her husband of 70 years. He is very frail and suffers from moderate dementia. SG is a small, slender woman. Her posture is straight and erect, but walks with a walker for safety. Although she smiles frequently, she cannot hide the sadness evident on her face. SG's father died when she was nine years old. The family moved from Brooklyn to Westchester but moved back to Brooklyn. SG said

"What troubles me is that I can't bring up wonderful memories... It is sad.I have no happy moments except a couple with my father before he died. We used to walk the Williamsburg Bridge on Shabbos (Sabbath)... We used to go into the shtiebel, (Yiddish for little synagogue,) and of course all the men made a fuss of me because I was a beautiful fat little girl" ...He would take all the kids to the candy store, all of us."

SG married soon after graduating high school. She and her husband had four children. With the children in school, SG earned a certificate in interior design. SG and her husband made Aliyah, (immigrated to Israel) in 1971. She said that she did a lot of volunteer work there. "A lot with the museum and a lot with antique shops. Archaeological... It was just, the best time of my life. Most exciting." The couple returned to New York soon after the 1973 Yom Kippur War. "It was getting very expensive, we couldn't afford it anymore...Because we were traveling so it cost a lot of money going back and forth, back and forth." The couple moved to Queens New York. Both SG and her husband commuted to work in Manhattan.

In 2003 one of SG's daughters died of cancer. This daughter's husband died of cancer, 10 years earlier. "It was horrible and he was dying, she discovered a lump on her breast. She had to have a mastectomy... It's a story that is unbelievable, horrible story... Just getting adjusted to being back in the United States. It was terrible." Some 20 years later, the couple retired to a 55+ community in Central New Jersey. They then moved from that community to here. "It was the best choice we ever made". 


\subsubsection{The Improved}

$\mathrm{CH}$, (respondent 14, improved.) $\mathrm{CH}$ is a 91-year-old Protestant married woman. She is one of two children She lives with her husband of 69 years. They have four children, all boys and twelve great grandchildren. $\mathrm{CH}$ reports that her children and grandchildren visit often,

"Not all at once, that would be nice, but very hard. The children give an enormous amount of time and help... I don't even have to ask. For instance, you can't see any of what I have but there are little sticky notes up on the cabinet doors for my husband that our kids put up... There's labels on the cane and on the cabinets, and you look around and that's just typical. I have a folder for our tax papers, put them all in there and they just take care of everything... anything. You need to see that doctor. I don't have to ask, I'm going to take you. I can't ask for nothing more."

$\mathrm{CH}$ was a middle school teacher until she retired at the age of 65 . She was also very much involved in the church including teaching Sunday School. $\mathrm{CH}$ and her husband's spirituality is apparent; they support more than 60 charities. $\mathrm{CH}$ continued to chair a church committee until just a few months prior to being interviewed. She cares for her husband who is physically independent, but suffers from moderate/severe dementia. "I was in Health Care (skilled nursing) for a little while and he was just lost... lost. He just depends on me... This wasn't in our plans... I just look at him... he is not the same. $\mathrm{CH}$ notes that although she had heart surgery 20 years earlier, she has no real health problems with the exception of hypertension."

"My father had cancer, and my mother, and my mother and all the women... all her sisters... had heart problems. My sister and I each have heart problems... strong strain of heart disability in my mother's family. My mother died of heart problems. My son just had heart surgery. Actually, I had very little problems. I had heart surgery 20 years ago and haven't had no real problems except blood pressure which is flaring right now."

$\mathrm{CH}$ was taking three classes, yoga, tai chi, and meditation. However, just recently she developed three compression fractures. She said that the pain from the fractures has become difficult to manage. "I just want to stay on my feet for another five years at least. I want to see my grandkids graduate from college get married and whatever."

MK, (respondent 18, improved.) MK is an 83-year-old Catholic widow female. She is one of eight children; four are living. MK graduated high school and earned a junior college degree. Neither MK nor her boyfriend at that the time were Catholic.

"The two of us not being Catholic went to learn about the Catholic religion and of course the priest who wanted to know which one of us is Catholic. And we said neither one of us; we're just here to find out what the church is about. And he thought that was interesting. I decided at one point that I 
wasn't going to marry, I was so interested in the Catholic religion that I decided for whatever reason G-d wanted me to become a nun and I had to say to (my boyfriend) I'm sorry but this is it. He said I'm not going to wait for you, you know. I said I don't expect you to do that; so I entered and stayed for 30 years."

MK became a nun. One of her responsibilities was managing the CCD program, (The Confraternity of Christian Doctrine) at the church. While a nun she earned her Master's Degree. She left the convent in her early 50's but continued to work as a lay schoolteacher managing the CCD program at the church. MK made friends with another lay teacher at the church. They became quite close. MK often accompanied her friend and her husband on vacations. MK's friend died a number of years later. She became even closer to her friend's husband as they mourned their shared loss together. Two years later they married. The couple moved to a 55+ community near the CCRC. He died six years later. Soon after MK decided to move to a CCRC. She continues to drive and volunteers at a local hospital. "I wear my little blue jacket to serve and just run around and say 'you are?"' She attends Mass every other day of the week. She also serves in the communities' gift shop weekly. "I'm happy here... keeps you busy." MK says that she hopes that when she dies she

“dies peacefully and quickly and that I don't have to go through hell. That is a concern I try not to dwell on, like how am I going to leave this earth? I'm happy here and I do continue my religious beliefs. I should do more on that... I have to remember that. No, my concern would be, how am I going to depart this earth?"

PP, (respondent 25, improved.) PP is a 77-year-old Catholic female widow. She is one of two daughters. Her younger sister died in 2011. PP has a master's degree in English Literature.

"My father thought I was too young to go to work. Well, he wanted college but then he said his only requirement was that I learn how to cook and sew. Well, I got a D in cooking so that wasn't so good."

PP married her husband shortly after graduating from college. The couple lived in Missouri for six years. They subsequently moved to Long Island, moving to three different towns before finally moving to New Jersey. PP returned to work when her youngest was a freshman in High School.

"I had to beg could I please go back to work. Oh, my G-d, Oh, yes. And he finally said yes, but I had to do everything I always did before... He was very old fashioned and also very prudish. He didn't believe work and family were together... But he let me go back to work and I loved it and of course after he died it was a godsend. I needed something really to do so it was great. I loved work."

PP's husband died in 1995 at the age of 59. They were married for 35 years. 
PP reported that she enjoyed gardening and was president of the local gardening society. She was responsible for the flower show for over ten years, until after her second stroke a few years ago.

"I've lived alone in that house in for all these years and alone with my dog. I had a fairly big house and I really couldn't take care of it any longer. Last year I had a stroke but I had one before that so I had two strokes and then last year I had the second one and shortly after that I broke my foot. Oh, G-d, and ended up in a wheelchair and the kids didn't know what do with me. I had a lady that came in the morning and afternoon and then my kids said you cannot stay at home. So, I went to live with my youngest daughter. She had two kids, they're teenage girls, three dogs, three cats and I couldn't tell you the number of fish and birds. Oh, (their) house is wild, but they were wonderful. We were already signing into a contract to have a room built on the house and decided we couldn't live together. I needed more than a room but having an old lady around the house with teenagers and everything they needed freedom so my son started looking and found this place..."

"I said well, I need a place to live and I can't take care of it. I had a big house and I had somebody that took care of the lawn, took care of the driveway, clearing snow, but it wasn't enough. So, I redid my downstairs last year and then my daughter-in-law and I decided to move here so I sold the house..." "So, I came here and things were suddenly all changed. I enjoy people again. I play scrabble. I play Rummikub. I want to learn to play Canasta again. It's been years but I'd love to play it again. I promised my children I would keep an open mind and try to partake and I'm trying. I can't bear to sit in the lobby and just sit and talk. I hate that but I'm trying. I go to the exercise center, the fitness center. I can't wait for good weather to take a walk and that kind of thing. Just day-to-day. What can I say? I don't know. I think I turned over a new leaf. I changed my way of life. My kids said, I was in a depression and I think I didn't realize it and comprehend that for a long time but I didn't realize it..."

"No, when I graduated from college I was a goody good person. It never entered my head to anything that would not please people. I did whatever seemed right. I went to a girls' college run by nuns, and it just didn't enter my head to be rebellious or different. Whatever was expected I would do..." "No, I'm much more adventurous today on that but I feel like I'm too old but after I meet some people around here I wonder. No, my sister and I were both very good girls. That's all I can say. I look back and I think why or why did you ever listen to this or why did you not question it and such."

PP continues her interest in literature as a resident of the community. She is a member of the library committee, the book club and Dickens Group. PP says that she regards this "as a place to come and wait to die. It's a pleasant wait though, much like Florida." 
GH, (rGH, Respondent 17, improved.) GH is a 99-year-old single Protestant female. She is an only child. Her parents moved from New York City to New Jersey when she as an infant. She remained in that house until she moved to a $55+$ community in 1977. GH graduated from high school and did office work. "I wanted to be an opera singer. I wound up in a bank and I used to walk through the halls and I say what in the hell am I doing here?" GH said that she did sing some in her youth. She was asked if she had performed professionally. With a sardonic smile, GH said she that performed "Very unprofessionally... My father managed to get me a couple of concerts, rare, very minor things, like at clubs who probably didn't know if you hit a wrong note or not." GH went to college (Ivy League) at the age of 47 graduating in 1969. She spent much time traveling:

"I've been all over the world twice. I've been to Europe 20 times I guess, Germany, England, Ireland, Wales. We rented Villas. I rented an apartment one time, a friend and I in Paris for a month. I was waiting on a corner one evening in Paris and two women came up to me and made me scram. They were ladies of the evening and thought I was cutting in on their territory..." "I've been to Siberia, New Zealand, Australia, Pakistan, Afghanistan, India, Kashmir, South Africa, and Kenya. I've been around. I went to the Far East by myself. I went to... well I was a tourist and I went to Russia by myself the first time. The second time I went, I went with a friend. The thing I like to do best is travel, after music that is. But then that's what's one of the things that's bugging me now. My body won't travel. My brain travels."

GH discussed why she moved to a CCRC.

"I used to audit courses at Princeton and then I went to the Opera and I went to New York. Then I went to plays on Broadway, I went to New York every two months at least. In between I traveled and then I got bored not doing anything... so I got a bunch of temp jobs. I wanted to play golf I couldn't. I couldn't even get a decent drive off..."

"I needed the services I get here. I don't have to cook although I used to love to cook. But if you get older your desire becomes less for a lot of things. It got to be a lot of trouble and then I sort of gave up eating. I got bored with eating and the circumstances demanded that I move. There was no other way out. It was either going to be sooner or later."

Still, GH keeps very busy. She had audited courses at the local university. Although she said that has become harder with "600 people competing to audit the same course." Still, she very frequently attends concerts at a number of local theaters and takes at least one college course a semester at the town's community center.

"Well, now I have to find someone to go with me because like I want to go to the movies. I'm afraid about going by myself. Isn't that crazy? So, I have to find somebody... I mean my friends are all dead or they're very sick." 
With a mischievous smile, GH said that:

“I just don't see any point in living. There's nothing's exciting like it was. No. I had no goal. I mean it used to be that I'd have a trip to plan and so that was exciting. But what am I going to do now? I'm going to the movies next week but that's all. It's not enough. Listen, take my advice, don't get old, whatever they tell you, it ain't fun."

\subsection{The Research Questions}

The research questions suggested that some women who have moved into CCRC's seem to remain healthier both emotionally and physically longer than other women. Although about the same in health at the time of moving into the community, they appear to rapidly deteriorate within the first six months of moving in. Health and well-being have been proven to correlate with one's roles. Are healthy people more likely to possess more roles, or are they likely to be engaged in more roles because they are healthier? A life course perspective should illustrate the interplay of timing, process and context on those roles, which foster health and well-being. Does a change in health, even a dramatic one, adequately account for the decline demonstrated on the SF-36? Would consistency in the work force or on a single trajectory have forestalled decline?

The five residents who deteriorated are college educated but otherwise demographically dissimilar. Three are Jewish, two are Protestant. Three are currently married; two are widowed. Hypothesis One proposed that healthier women have maintained at least one role consistently longer than less healthy women associated with the life course perspective of timing. Hypothesis two proposed that the roles longest held by healthier women in their earlier years have been transformed into other roles held over into old age, (process, role trajectory). These hypotheses seem supported in light of the four residents who improved.

Respondent 14's coding frequencies highlight a number of significant areas; children, loss, and roles relating to jobs, loss and transition. However, loss and roles warrant further analysis since changes in those areas appear to relate to changes in the CH's situation, (compression fractures and pain) since completing the second survey. Respondent 14 became a teacher and remained a teacher until retirement. She was a vibrant, involved member of both her religious community and the CCRC until she became ill.

Similarly, respondent 18 also supports hypothesis one. Coding frequencies suggest religion, and roles both in jobs and transitions. Even though MK was not born Catholic, she converted to Catholicism and became a nun. She taught in a Catholic School and although she later left the order, she continued to teach. She remains in a service role, working as a volunteer in a local hospital. "I'm happy here and I do continue my religious beliefs. I should do more on that... I have to remember that."

Respondent 25 also improved. Her coding frequencies point to the areas of disease, mood, roles in the job and transitions. PP experienced emotional and 
physical loss, suffering a devastating stroke and subsequent depression. The salient point may be PP's long-standing longing to work.

"I had to beg could I please go back to work. Oh, my G-d, Oh, yes. And he finally said yes... But he let me go back to work and I loved it and of course after he died $\mathrm{t}$ was a godsend. I needed something really to do so it was great. I loved work."

For PP work was the role she most enjoyed and the move to a CCRC the catalyst. PP declares, "so I come here and things were suddenly all changed. I enjoy people again." PP is involved in a number of table and card groups and a Dickens book club. "I promised my children I would keep an open mind and try to partake, and I'm trying."

One significantly frequent code for respondent $17, \mathrm{GH}$, is education. Less frequent, but nonetheless noteworthy are housing and travel. GH lends much consideration as to where she lives as opposed to how times she moved. She actually only moved three times remaining at the last two homes for 98 of her 99 years. Travel is much more significant as she mentioned having been "all over the world twice and to Europe over twenty times."GH earned her degree in her 40 's and has continued to take college courses since, each and every semester. This has included auditing courses at Princeton University and at a local community center. She went to Broadway Plays and the Opera at least bi-monthly. She continues her interest in the arts attending opera productions played in local movie theatres and local music and theater in a host of local cultural centers. Education and the arts continue to be paramount. It is noteworthy to mention that the roles of the four individuals who were identified as having improved $\mathrm{CH}, \mathrm{GH}, \mathrm{MK}$ and PP were played in a social context. None of the four respondents could be seen as introverted. PP commented, "I thought oh, old people are really not interesting but they are. They're very fascinating."

Hypothesis one, healthier women have maintained at least one role consistently longer than less healthy women and hypothesis two, the roles longest held by healthier women in their earlier years have been transformed into other roles held over into old age, is further substantiated by each of the five respondents that deteriorated. The coding frequency table for Respondent $\mathrm{CH}$ highlights two significant areas: jobs and disease. $\mathrm{CH}$ changed jobs many times over the years. She had six separate job changes, mentioned six times. Although teaching seemed to be her avocation, she experienced two job changes with this as well. The most striking other code frequency was in the area of health. This is not surprising as $\mathrm{CH}$ attributes developing myasthenia gravis as the precipitating factor to her decline.

DD's coding frequency table points to a number of significant areas: death, education, changes in jobs, housing, and particularly relationships. She mentioned moving many times during her childhood. She changed jobs many times prior to marriage and only worked inconsistently after marriage. Although education seemed to play be a major role satisfaction, it did not appear to provide 
the sustenance necessary to quell the onslaught of tribulations in her relationships, particular to her mother, with her husband and their autistic child. DD is a reclusive, uninvolved, rather morose, older adult.

On the surface, EW's deterioration appears to be an anomaly. Her frequency code table presents a number of reoccurring themes, in education, relationships, and role trajectory. She recounts a pleasant childhood. EW experienced a number of transitions, in moves and with work, even moving from state to state. However, she aspired to be a librarian from childhood and spent her entire adult life in her in avocation in paid and unpaid positions. Religion equally played an important part as a child and as adult. Her failing health at the age of 97 and at the time of moving to the CCRC seems to be the critical explanation for her deterioration.

MF's significant code frequencies are religion, jobs and role transitions. MF was raised in a family in which religious tradition played an important part. MF attended parochial school through high school, attending the same church her mother married in. However, a number of significant events occurred. Her husband contracted tuberculosis soon after they married. MF cared for their newborn alone. Her son died in the World Trade Center attacks on September 11, 2001. Her husband died 10 years ago. She acknowledges that she "rolls with the punches... What can I do?" MF appears to live her life on the periphery, an observer rather than the participant in her relationships and in her life. Such would seemingly account for the paucity of roles and her apparent deterioration.

SG's code frequencies indicate disease, housing, mood, and particularly transition. She reported that she didn't have a happy childhood; her mother was always sad. Her father died when she nine. She moved a number of times when she quite young. She and her husband made Aliyah to Israel, only to move back to the US and then move three additional times. SG's daughter died, as did her daughter's husband. SG endured an onslaught of emotional assaults throughout her life, from which she rebounds poorly, if at all. The only time she appeared to latch onto an enriching role was when working as a volunteer in an Israeli museum. SG is a sad and reclusive resident.

Hypothesis three suggests the longest held roles of healthier women were subject to fewer assaults of circumstances, i.e., finances, disease, death of family members, etc., than those of less healthy women (context). Hypothesisfour, stipulates that women who held roles the longest have been the beneficiaries of more positive circumstance, such as financial security and education (context). Neither of these hypotheses seem supported by this research. Respondents 16, 32 17,18 , and 14, two respondents who deteriorated and three who improved all seem to have had the least assaults of circumstance, losses such as the death of a family member or health issues, while respondent 6 experienced an abused childhood, the birth of autistic child and less than a happy marriage, respondent 8's son died on "9/11" and 25 suffered a less than satisfying marriage and a devastating stroke. Similarly, for hypothesis four, with the exception of respondent 
11, all respondents are college educated and have benefited from at least a middle income to upper middle income and resources or they would not be at a CCRC. Therefore, there is nothing seemingly remarkable to distinguish any of the respondents from one another. In this instance respondents form a self-selecting sample.

\section{Discussion}

As earlier indicated, the literature is replete with studies demonstrating that the quantity and quality of roles are positively correlated to health (Lowenthal \& Haven, 1968 [22]; George, 1966 [23]; Throits, 1983 [24]; Verbrugge, 1983 [25]; Moen et al., 1992) [2]. But are healthy people more likely to possess more roles, or are they likely to be engaged in more roles because they are healthier (Wethington et al., 2000) [1]? The study appears to answer the quintessential question: how do we account for healthier older adults who do not possess multiple roles? The study supports previous findings that membership in roles promotes health and well-being but the quantity of roles may be equal to or even less a factor than consistency of membership in even a single role. The push for older adults to be involved takes on a new meaning. Involvement in even one role... one single role, can significantly improve the quality of life for a resident. While membership in many roles has been proven to enhance the quality of life for older adults, membership in a single role may offer the same benefits.

Adult communities should seek to glean as much knowledge as possible as to past roles, and particularly role consistently over time. The community would be prepared to support those roles and therefore the quality of life of the resident. Rather than offering many opportunities for involvement in activities, communities must help to steer residents to role opportunities, opportunities to embellish or nurture previous roles. It is essential to note that attending a lecture, watching a movie, attending a party, playing cards etc., are not necessarily roles. These are examples of activities. An activity can enhance a role, but by definition an activity is a pursuit, an interest, a pastime or recreation. Playing cards is an activity, and yet the role may be that of a card player. The activity describes the action; the role identifies who we are. Playing cards could enhance the role of a card player, but the activity of playing cards for others is merely an activity. Therefore, the challenge for adult communities is to create opportunities for meaningful role involvement rather than to simply offer exhaustive lists of activities. The potential to significantly improve the quality of life to those heretofore found to have deteriorated is staggering. Similarly, residents whose health and well-being has diminished since moving into the community can be evaluated for past role involvement. Efforts to involve these individuals in meaningful roles offers a simple, yet potentially powerful tool to significantly improve their quality of life.

No one would refute the potential benefits of providing supportive services to older adults. The issue is less one of individual benefit than one of cost benefit. 
Does the benefit outweigh the cost? Clearly providing supportive services to all older adults involved in moving would yield a benefit. But does the benefit to the individual outweigh the financial cost to the community? It clearly appears that is does. On a national level the cost of providing health services to older adults in 2009 was estimated to be $\$ 1.26$ trillion for just those who are not institutionalized (US Department of Health and Senior Services, 2012) [31]. This equates to 105 billion a month, 3.5 billion dollars a day, or \$1070 for every man, woman, and child each day.

Of particular significance to the study of roles to health and well-being is evidence that the SF-36 self-evaluation health transition item not used in summary measures is useful in estimating average changes in health status during the year prior to administration of the test. While this evidence is encouraging for evaluating changes in health throughout a longitudinal study, caution must be exercised as change has been documented only in comparison of self-perceptions of change at a summary level (Ware, 2000) [32].

Although the study seeks to understand the impact of relocation on residents with varying number of roles, the sampling frame consisted of women who recently moved to independent living in a CCRC. While individuals in other populations may be exposed to similar circumstances, there are likely key differences between this sampling frame and that of male residents. Recruitment of residents occurred throughout the year.

Purposeful or extreme case sampling was used which also limits the ability to generalize the results of the study. One of the benefits of using a small sample size is that the researcher was able to conduct in-depth interviews with residents to obtain qualitative data. It would not be rather laborious to collect data with this level of detail from a larger sample. One disadvantage of the sampling strategy is that it focused on the healthiest and least healthy individuals, as determined by a screening tool. The qualitative interviews were conducted with extreme cases, rather than with individuals who may represent typical CCRC residents. Since only women are entered into the study, any inferences drawn from this research must be limited to women. Moen (1996) believes that gender does matter. She postulates that historical changes in women's roles with consonant expanding role-options provide for greater heterogeneity in retirement than for men. Therefore, the disparity in life paths and the implications for health may differ by gender (Moen, 1996) [21].

There are a number of threats to internal validity. One such threat is mortality. Given the age of residents, some may expire from the time of admission to post-test six months after admission. Obviously, attrition by death cannot be controlled for. Experimental bias may also be a threat. Those providing the surveys may inadvertently affect data by "helping" to influence results to desired (hypothesized) outcomes. Attempts to control this would be made by providing detailed and systematic training. Additionally, resident testing and then re-test is also a threat to internal validity as residents may "learn" the test from the first 
testing. However, it is believed that residents would have little carryover of learning between test and retest due to the six months of time between sessions.

There are questions as to whether the results of this study with women who have moved to congregate CCRC housing is representative of moves of older adult women to other types of congregate housing or who choose to remain in their own homes. Such a threat to external validity challenges generalizability. The study sample was drawn from residents of a particular continuing care retirement communities. Moreover, admission to a continuing care retirement community is limited to those individuals with significant financial resources. As noted, with the exception of respondent \#11, all respondents have benefited from at least a middle income to upper middle income and resources. Maturation, the natural change that comes with growing older is another threat to internal validity was. Of the 38 , one died before the time of the six-month survey, one was unable to complete the second survey due to time constraints, two refused to complete the second survey due to caregiving responsibilities of their spouse, one decided not to continue her involvement for unspecified reasons. Older adults are obviously more at risk for such changes especially in a population with a mean age of 86 . This was especially evident with $\mathrm{CH}$, respondent \#14. Soon after completing the second survey, only six months after moving into the CCRC, $\mathrm{CH}$ experienced a number of compression fractures drastically altering her independence and involvement. There are also a number of methodological limitations. Both the quantitative and qualitative portions of the study consist of small samples. Given a possible sample of over 150 individuals who moved into the five CCRC's within a six-month period, less than a fourth (0.25) agreed to participate. The offer of a \$25 VISA Gift Card, up from a \$5.00 Dunkin Donuts Gift Card did to spur an increase in the number of volunteers but still fell far short of expectations. Additionally, the lack of prior research and data posed methodological issues. There is a lack of data for comparison and analysis, which limits the scope of the study. The fact that the surveys were based on self-evaluations and that the information collected from individuals from interviews was self-reported is a major methodological issue. Self-reported data has several potential sources of bias:

1) selective memory (remembering or not remembering experiences or events that occurredat some point in the past); 2) telescoping [recalling events that occurred at one time as if they occurred at another time]; 3) attribution [the act of attributing positive events and outcomes to one's own agency but attributing negative events and outcomes to external forces]; and, 4) exaggeration [the act of representing outcomes or embellishing events as more significant than is actually suggested from other data" (Cohen, Manion \& Morrison, 2000) [33].

Future studies should attempt to involve larger samples. Studies would also benefit from the inclusion of males. Since this study was limited to women moving into a continuing care retirement communities, future studies could 
examine the nature of roles on men moving to congregate housing. Attempts should also be made to examine older adults in different settings. Moreover, moving to a continuing care retirement community requires substantial financial resources. There are some 1900 CCRC's located in the contiguous 48 states and the District of Columbia of the US. Roughly half are faith based; over $80 \%$ are not-for-profit. The average age of residents at move-in is 81 years; two thirds are women. More than twice as many residents have a college degree compared to the US population. New independent living residents report annual incomes from $\$ 10,000$ to $\$ 200,000$, with more than $32 \%$ reporting incomes between $\$ 50,000$ to $\$ 99,000$. Half of all residents report a net worth in excess of $\$ 300,000$ (Smith, 2003) [34]. It would therefore be noteworthy to learn if financial wealth and education are contributing factors to health and well-being with older adults who have moved to congregate housing. It would also be important for a follow-up study to examine if those residents identified as having deteriorated, significantly improve after supportive intervention of membership into single roles. As all four respondents identified as having improved were sociable and involved in community life, a future study could assess whether this was coincidental or a contributing factor as to the nature of role involvement. Moreover, while the study demonstrated that membership in a single role may offer the same benefits in enhancing the quality of life for older adults as membership in many roles, the quality of the role may play an equally or greater function. Membership in a single role may enhance the quality of life of an older adult, but the degree of satisfaction with that role may be an even greater mitigating factor. Additionally, it appeared that women who experience fewer role changes, remain married and experience less loss also do better emotionally and physically. The study also did not examine the impact of religion and spirituality on health and well-being. Future studies could seek to measure the degree of role satisfaction with single roles and the factors associated with role consistency and loss on health and well-being.

\section{References}

[1] Wethington, E., Moen, P., Glassgow, N. and Pillemer, K. (2000) Multiple Roles, Social Integration, and Health. In: Pillemer, K., Moen, P., Wethington, E. and Glasgow, N., Eds., Social Integration in the Second Half of Life, The John Hopkins University Press, Baltimore.

[2] Moen, P., Dedmpster-McClain, D. and Williams, J.R. (1992) Successful Aging: A Life Course Perspective on Women's Multiple Roles and Health. American Journal of Science, 97, 1612-1638. https://doi.org/10.1086/229941

[3] Elder, J.G. (1985) Life Course Dynamics: Trajectories and Transitions 1968-1980. Cornell University Press, Ithaca.

[4] Elder, G. (1995) The Life Course Paradigm: Social Change and Individual Development. In: Moen, G.E. and Luscher, K., Eds., Examing Lives in Perspective, Washington DC.

[5] Boyle, P., Halfacree, K. and Robinson, V. (1998) Exploring Contemporary Migration. Wesley Longman Limited, Harlow. 
[6] Walters, W. (2002) Later-Life Migration in the United States: A Review of Recent Research. Journal of Planning Literature, 17. https://doi.org/10.1177/088541220201700103

[7] Litwak, E. and Longino, C. (1987) Migration Patterns among the Elderly: A Developmental Perspective. The Geronotological Society of America, 27, 266-272.

[8] De Jong, G., Wilmoth, J., Angel, J. and Cornwell, G. (1995) Motives and the Geographic Mobility of Very Old Americans. Journal of Gerontology. Social Sciences, $50,3.1,4.1,4.4$.

[9] Oswald, F., Schilling, O., Hans-Werner, W. and Karen, G. (2002) Trouble in Paradise? Reasons to Relocate and Objective Environmental Changes among Well-Off Older Adults. Journal of Environmental Psychology, 22, 273-288. https://doi.org/10.1006/jevp.2002.0255

[10] Folts, E. and Muir, K. (2002) Housing for Older Adults: New Lessons from the Past. Research on Aging, 24, 10-28. https://doi.org/10.1177/0164027503024001002

[11] Folts, W. and Streib, G. (1994) Leisure Oriented Retirement Communities. In: Folts, W. and Yeatts, D., Eds., Housing and the Aging Population: Options for the New Century, Garland Press, New York.

[12] Golant, S. (1984) A Place to Grow Old; the Meaning Pf Environment in Old Age. Columbia University Press, New York.

[13] Lawton, M. (1975) Planning and Managing Housing for the Elderly. Wiley, New York.

[14] Mangum, W. (1994) Planned Housing for the Elderly since 1950: History, Policies and Practices. In: Folts, W. and Yeatts, D., Eds., Housing and the Aging Population: Options for the New Century, Garland Press, New York, 25-58.

[15] Pynoos, J. (1994) Public Policy and Again in Place: Identifying the Problems and Potential Solutions. In: Tilson, D., Ed., Aging or Need? Public Policies for Older People, Garland Press, Newbury Park, 131-169.

[16] Streib, G.F., Folts, W.E. and Hilker, M.A. (1984) Old Homes-New Families: Shared Living for the Elderly. Columbia University Press, New York.

[17] Longino, C., Perzynski, A. and Stoller, E. (2002) Pandora's Briefcase: Unpacking the Retirement Migration Decision. Research on Aging, 24, 29-49. https://doi.org/10.1177/0164027503024001003

[18] Nelson, L. and Winter, M. (1975) Life Disruption, Independence, Satisfaction, and the Consideration of Moving. The Gerontologist, 15, 1960-1964.

https://doi.org/10.1093/geront/15.2.160

[19] Wiseman, R. and Roseman, C. (1979) A Typology of Elderly Migration Based on the Decision Making Process. Economic Geography, 55, 324-337. https://doi.org/10.2307/143164

[20] Silverstein, M. and Zablotsky, D. (1996) Health and Social Precursors of Later Life Retirement-Community Migration. Journal of Gerontology: Social Sciences, 51, 150-156. https://doi.org/10.1093/geronb/51B.3.S150

[21] Stoeckel, K. and Porell, F. (2010) Do Older Adults Anticipate Relocating? Journal of Applied Gerontology, 29, 231-250. https://doi.org/10.1177/0733464809335595

[22] Lowenthal, M. and Haven, C. (1968) Interaction and Adaptation: Intimacy as a Critical Variable. American Sociological Review, 33, 20-30. https://doi.org/10.2307/2092237

[23] George, L. (1996) Social Factors and Illness. In: Binstock, R. and Georeg, L., Eds., Handbook of Aging and the Social Sciences, 4th Edition, San Diego. 
[24] Thoits, P. (1983) Multiple Identities and Psychological Well-Being: Areformulation and Test of the Social Isolation Hypothesis. American Sociological Review, 48, 174-187. https://doi.org/10.2307/2095103

[25] Verbrugge, L. (1983) Multiple Roles and Physical Health of Women and Men. Journal of Health and Social Behavior, 24, 16-30. https://doi.org/10.2307/2136300

[26] House, J., Landis, K. and Umberson, D. (1988) Social Relationships and Health. Science, 241, 540-545. https://doi.org/10.1126/science.3399889

[27] Pillemer, K., Moen, P., Wethington, E. and Glasgow, N. (2000) Social Integration in the Second Half of Life. The Johns Hopkins University Press, Baltimore.

[28] Lin, N., Ensel, W. and Gina Lai, W. (1997) Construction and the Use of the Life History Calendar: Reliability and Validity of Recall Data. In: Gotlib, I. and Wheaton, B., Eds., Stree and Adversity over the Life Course: Trajectories and Turning Points, Cambridge University Press, 249-272.

[29] Giele, J. and Elder, G. (1998) Life Course Research: Development of a Field. In: Giele, J. and Elder, G., Eds., Methods of Life Course Research: Qualitative and Quantitative Approaches, Sage Publications, Inc., Thousand Oaks. https://doi.org/10.4135/9781483348919.n1

[30] Glaser, B. and Strauss, A. (2012) The Discovery of Grounded Theory: Strategies for Qualitative Research. Aldine Transaction, New Brunswick.

[31] US Department of Health and Senior Services (2012) Agency for Healthcare Research and Quality. http://meps.ahrq.gov/mepsweb/data_files/publications/st355/stat355.shtml

[32] Ware, J. (2000) SF-36 Health Survey Update. Spine, 25, 3130-3139. https://doi.org/10.1097/00007632-200012150-00008

[33] Cohen, L., Manion, L. and Morrison, K. (2000) Research Methods in Education. 5th Edition, Routledge Falmer, London and New York. https://doi.org/10.4324/9780203224342

[34] Smith, D. (2003) The Older Population in the United States: March 2002. U.S. Census Bureau Current Population Reports, 20-546.

Submit or recommend next manuscript to SCIRP and we will provide best service for you:

Accepting pre-submission inquiries through Email, Facebook, LinkedIn, Twitter, etc. A wide selection of journals (inclusive of 9 subjects, more than 200 journals)

Providing 24-hour high-quality service

User-friendly online submission system

Fair and swift peer-review system

Efficient typesetting and proofreading procedure

Display of the result of downloads and visits, as well as the number of cited articles

Maximum dissemination of your research work

Submit your manuscript at: http://papersubmission.scirp.org/

Or contact jss@scirp.org 